Psyke \& Logos, 2007, 28, 271-287

\title{
HEALTH AND MUSIC IN EVERYDAY LIFE \\ - a theory of practice
}

\author{
Tia DeNora
}

\begin{abstract}
Denne artikel er baseret på isar to undersøgelser foretaget af medlemmer af Kunst-sociologi-gruppen ved Exeter University (UK). Undersфgelsernes fokus er almindelige menneskers anvendelse af musik ('lay-musicking') [Begrebet 'musicering' (musicking) refererer til C. Small m.fl.s tolkning af 'musik' som en interpersonlig aktivitet mere end et objekt]. Data fra undersøgelserne bruges som afsat for udvikling af en teori om musikkens psyko-kulturelle rolle og funktioner som et kommunikations- og regulerings-medie, og som et redskab til at skabe mening i dagliglivets specifikke, tidslige kontekster. Der trakkes forbindelser mellem de processer, der kan observeres $i$ 'lag-musicering', og musikterapeutisk teori og praksis, og dette sker på en måde, der understreger, hvad musiksociologien kan lare af musikterapien og af lagfolks musicering inden for sundhedsområdet.
\end{abstract}

\section{Introduction}

This article is organized around two key tasks. The first is to outline the importance of everyday musical activity - musicking as Small (1998) termed it - in relation to health and well-being and to lodge that discussion in context of the growing body of work devoted to music's role as a health resource or 'technology of health' in daily life (Ruud 1997; 2002; DeNora 2000; BattRawden 2006a; 2006b; in press; Brown and Theorell 2006). The second is to conceptualize 'health' and 'illness' as environmentally-mediated and environmentally-sponsored performance. In what follows, the second task will be developed first, and the theoretical concepts this task provides will be used to conduct the first task. Overall, the argument, briefly stated, is that a constructivist perspective focused on everyday musicking, set in context of a broader understanding of health as socially produced in daily activity and within the various enclaves of daily experience, highlights music's importance as a resource of health management outside of, but arguably facilitated by, music therapeutic and/or quasi-therapeutic practice.

Tia DeNora. PhD. Professor of Sociology of Music and Director of Research, Sociology/Philosophy, University of Exeter. 


\section{Health as performed}

Within constructivist perspectives, health and illness are conceptualized as social facts, that is, their reality takes shape in ways that stand outside of individuals and is made known through the varied ways in which health is conceptualized, assessed, performed and perceived in social life. Health, in other words, is 'known' according to socially recognized indicators of ability, capacity, and condition as these are demonstrated by actors to self and others in varying modes of interaction (Mehan et al 1986; Goffman 1961; Radley 1984).

This is to say that health is performed in social settings and in relation to performance conventions and materials. For example, in some countries today, when we visit a health professional - for a medical check-up, let us say - we submit ourselves to a battery of tests (blood pressure, heart rate, cholesterol, and so on). We then receive an assessment (like a report card) of how 'healthy' we are in relation to established measures. Our 'bad' cholesterol is low, our blood pressure 'perfect', our short-term memory is failing, we are experiencing 'mild depression'. When we repeatedly 'pass' or 'fail' the tests designed to ascertain these things, we are deemed, by medical practitioners, to be healthy or ill. Health, in other words, is indicated by the passing of some tests or trials that accord with cultural conceptions of what it means to be healthy. When we have achieved a good 'report card' time and time again, we accumulate an identity - we are 'healthy'. Health, in other words, is health-status. We are apportioned degrees of this status according to how we repeatedly perform in the various trials and tests that are set for health-assessment. (It bears noting that there will be many other tests, some in existence, some only imagined, some we probably could never imagine, that will be conducted. The omissions are equally interesting to the social study of medical science.)

Crucial here is that health measurements are meaningful to those they describe. That is to say that the social act of, for example, making reports, prognoses and the offering of treatment interventions may itself recontextualize our perception of our physical being. These recontextualizations are in effect new meanings and new beliefs, and recent research has suggested that these 'placebo effects' may be linked to actual physiological changes in ways that highlight the power of belief, suggestibility and associated 'mindbody' interactions (Zubieta, et al 2005). Certain beliefs may, in other words, provide active ingredients of future health-status, and they may facilitate or hinder future health-performances, including those that can be assessed physiologically.

To take some simple examples: individuals may experience a 'lift' after being told that their health has improved or that a medicine will help them: they may, from that moment and for some interval of time, feel more 'positive', experience greater energy, and/or greater motivation to continue with 
some form of health-regime. Conversely, they may feel despondent on receipt of 'bad news' and so be more likely to adopt the 'sick role'. Alternatively, the cognitive 'certainly' associated with an official diagnosis, may bring relief, especially if they have lived with undefined illness for some time, even when the diagnosis is itself 'bad news' (Hilbert 1986). In all of these examples, recognized health-statuses have (potential) recursive power; they are part of an in-put loop in health-performance insofar as they may structure capacity for healing and recovery, and the phenomenological experience of 'symptoms', including pain, both phantom and transcended. This theme, which will be developed below, is critical to the investigation of culture's role and its mechanisms in the construction of health and illness. It is vital to any consideration of music as an everyday health technology. First, however, it is necessary to expand the notion of health performance under development here.

Medical technologies of health assessment are only one way that health is registered and made known to self and other. There are others more mundane. We may 'know' our current health status by how we are 'able' to perform various tasks, even mundane tasks such as being able to climb stairs, hold a job (or a particular type of job), or feed ourselves, for example. All of these 'performances' show us (to ourselves and others) as able. They are demonstrative of health-status.

Reconceptualizing health in social, behavioural and dramaturgical terms (as health-status, health performance and health practices) illuminates health as an achieved, constructed, condition, socially situated in time and space. This reconceptualization points in turn to the question of health-pragmatics, that is to the practices by which 'health' is attained and maintained through various socio-technical and cultural actions. And this focus on pragmatic action in turn illuminates the question of resources: what does it take to produce repeated 'passings' as healthy, however these are registered. (For related theoretical literature on the pragmatics of performance in other contexts, see Chambliss 1990; DeNora 1991 and Garfinkel 1968). How, in other words, can we develop a grounded theory of health pragmatics? The next section of this article (part two of task one) considers each of these interlinked forms of resources in turn, so as to develop grounded, pragmatic theory of health-status as it is produced between rather than within individuals and between individuals, material culture and norms.

\section{Health as relational and socially distributed opportunities for performance}

We often think, in commonsense terms, that our criteria of health (how we register it, as described above) are not culturally and historically specific and are not produced in the here-and-now of everyday occasions, time after 
time. When we operate in this way, we fall prey to a fallacy; we conceptualize 'health' as a simple 'matching' exercise, where instance is mapped on to category (e.g., a case of mumps, hysteria, lunacy, too much bile). This fallacy prevents us from recognizing how our categories of health are (a) not immutable, as some of the examples just stated highlight, but rather, historically specific and (b) not neutral and pre-given 'containers' but formative of our perception (recognition) and self-perception of health and illness. In other words, categories (of health/illness) provide a grid for perception, both prospectively and retrospectively (Mehan et al 1986); they call our attention selectively to some things while suppressing our sense of other things and they suggest arrangements, hierarchies and connections between things. Our criteria and categories of health and illness, in short, take shape within cultural meaning systems and different systems produce cognitive schemes of health and illness. These schemes both structure and are structured by institutionalized patterns of recognizing and dealing with instances of categories of health/illness. These schemes and patterns are what make forms of health and illness manifest as aspects of social reality. In these ways, health - its psychological and physical characteristics - is a collective and emergent matter, socially constructed. To speak of health as 'constructed' is not to deny the apparent reality of physical states (e.g., the spots we recognise as 'measles' or, the ability to complete particular tasks) but to recognize that their consequences are socially and technologically mediated.

For example, consider the health-status of being physically mobile. Mobility is a relational state and a meaningful state; it is not 'merely' a property of individuals but rather emerges from a series of practices and interactions with the built environment. This interaction - between humans and objects and between humans and categories of meanings - will augment or diminish ability/disability according to how the built environment is organized (Freund 2001). If curbs are converted into sloping surfaces, if traffic lights allow for longer crossing times at the 'walk' or 'green man' [sic] signs (or the aural signal that tells visually impaired people that it is safe to cross a road), if we do away with stairs, then the difference between wheelchair users and walkers is of less consequence. If, by contrast we raise curb height to three feet, we have not only created a barrier between those who are able to walk and those who aren't, we may also create a barrier between those who are able to climb and those who cannot. So too, technologies and normative assumptions about what counts as 'speaking' may determine who is or is not communicatively disabled. Nora Groce's study (2006) of how hearing impairment was, for all practical purposes, inconsequential in $19^{\text {th }}$-century Martha's Vineyard is a case in point. Because the material practices of work did not require spoken interaction and because, in her titular phrase, 'everyone here spoke sign language' the social impact of physical conditions, such as not being able to hear, was greatly diminished. This is to say that the social impact of physical and/or mental 'symptoms', as measured in and 
through a range of performances through which one passes as healthy or ill (not being able to hear or walk, not being able to rouse oneself to 'get on' with the playing of a social role, not being able to 'fight' a life-threatening tumour) is the experiential realm. It is this realm where health and illness matter and where they are lived as day-to-day 'realities'.

In both these cases (mobility; hearing impairment), social action is the realm where normative frames are routinely plied in ways that produce the identity of illness/health, that align features of our bodies, minds and their capacities with categories of meaning such as 'seriously ill', 'learning disabled', physically disabled' and so forth. These categories become 'real' (i.e., socially significant as types of health and illness) as they pass through the various social channels devoted to their recognition. In what ways, then, may actors seek to modify and/or stabilize normative frameworks and environments and thus, their health-status as known and experienced by themselves and/or others? And, to state the core topic of this article, how may music, in particular everyday musical activity, be understood as a technology through which this modification (simultaneously of self and environment) is achieved? The second half of this article seeks to answer these questions by considering three examples that highlight the importance of music in the mundane project of health-performance. In a nutshell, how can music in everyday life provide resources for health as everyday experience? To what extent are musical resources similar to the material and organizational resources so far discussed and to what extent are they different? Finally, to what extent does considering this question enrich current conceptions of the aetiology and management of health? In the next section, the theoretical groundwork for this investigation is clarified through the concepts of affordance and appropriation are introduced so as to provide the foundation for a theory of music as a technology of health.

\section{Affordance and appropriation}

If the performance of health-status is a relational, emergent and collective activity, one that takes shape with reference to environmental properties and normative procedures, how, then, should we understand the relationship between properties and procedures on the one hand, and health performances on the other hand? In what follows, the concepts of affordance and appropriation are presented in order to develop the theory of music as a health resource that will be presented in part two.

The concept of affordance, originally introduced by J. J. Gibson (1958), highlights the constitutive role of environment in action, perception and consciousness (Gibson 1958 [for discussions of the affordance concept in music studies see DeNora 2000; Clarke 2005]). Objects, materials and conventional patterns of doing things may lend themselves to some things 
and may make other things more difficult. Simply illustrated, a spherical object may be easier to roll than a cube, loamy (versus clay) soil may make it easier to grow root vegetables. The absence of curbs and stairs affords wheelchair mobility, their presence, the cognitive recognition of significant 'difference' between able bodied and dis-abled [sic], the unimportance of using speech for communication within a culture affords the apparent unreality of difference between people's capacity to hear.

But how do affordances come to afford? Objects do not »cause« actions or the ways to which they are oriented. They do, though, present structuring properties that enable and or constrain action, and through their access and use. Indeed, an object's or material's affordances may actually 'lead' individuals or groups to do things that they might not have intended, wished or thought about doing - simply because they can be done. This is to say that the opportunities that objects provide are made manifest through action. It is how we engage with objects that action is structured by those objects. In other words, clay soil does not 'cause' an absence of carrots; gardeners and farmers make that 'cause'. However, the presence of clay soil may provide an important factor that provides a condition of action: it is taken into account by farmers when they decide what crops to plant (whether as a conscious strategy [e.g., 'it will be too difficult to harvest carrots and they will not grow so well in this soil'] or as semi-conscious and embodied decision [e.g., the memory of the back-breaking work of pulling the crop up last time]. So too, slanted walk-ways, as opposed to steps and curbs, may afford mobility and the ubiquity of sign language may afford communicative inclusion and thus diminish the perception of 'disability'. In all of these examples, affordances are produced through an interaction between people, interpretations and decisions and the use of materials. Affordances are are the product of practices of appropriation, achieved in and through practical action and how to locate affordances may have to be learned. We are afforded help (or hindrance) from the objects around us, but simultaneously, we constitute those objects' affordances just as they constitute us and what we may afford - our capacities (and incapacities). This reciprocal and emergent feature of affordances highlights the role of human resourcefulness in their discovery.

We are now in a position to consider music's mechanisms of operation in daily life and its role as a medium that may afford health. Music's role as a health technology depends, in other words, on how it is appropriated and on what it affords through this process. In what follows, examples from two studies (both completed at or in connection with the Exeter Arts Sociology Group) will be used to develop a theory of music's role as a 'technology of self' (DeNora 1999; 2000) and a technology of health promotion and selfcare study (Batt-Rawden and Tellnes 2005; Batt-Rawden and DeNora 2005; Batt-Rawden, DeNora and Ruud 2005 Batt-Rawden and Aasgaard 2006; Batt-Rawden, 2006a; Batt-Rawden 2006b). 


\section{Music as a 'technology of the self'}

In her work on music in everyday life, based on participant observation and in-depth interview data in the USA and UK, DeNora (1999; 2000; 2001) has described how music comes to afford a wide array of uses in the various processes of mundane self-care and self-regulation. These uses range from emotional regulation and modification (sometimes as part of 'emotional work', understood as the bodily cooperation with an image of how one should feel/appear as an emotional being [Hochschild 1982]), to music's role as a prosthetic technology of the body, to the ways in which music functions as a template or exemplar for cognitive processes and knowledge formation. In this section, examples of each of these tasks will be considered in turn.

Consider 'Becky', describing how she uses music as a resource for recalibrating herself emotionally, prior to taking part in an evening activity:

Becky: If I was feeling particularly like I wasn't really looking forward to where I was going, then I would have to put something really lively on to try and get me in the mood.

Q. Where might you be going that you weren't really looking forward to?

Becky: Family gatherings [laughs]. Or some sort of meeting to do with the scouts, I tend to really not look forward to that. (Interview w. Becky, aged 26, UK)

Here, Becky describes how participation in social situations require certain emotional and embodied properties ('get me in the mood') that are features required of participants. To draw herself into the appropriate 'mood', she describes how she uses music as a tool of emotion management, in this case, to modify her current emotional state and heighten her mood. Music here is a resource that Becky uses so as to fulfill social responsibilities, to align her with what she perceives is required.

Over half of the fifty six interviewees (all women between the ages of 18 and 78), particularly those under forty, described how they functioned as 'DJs' to themselves, using music to configure and reconfigure mood, energy and social orientation:

[If I'm going to] sleep, sometimes I'll throw on a few tracks to wake me up, nice ' $n$ slow and then I'll throw on something else. And then, sometimes, you know, if I'm not really, not in that relaxed mood, I'm like you know, 'I don't wanna [sic] listen to that' and I'll throw something fast on, or something fast is playing and I'm like 'That's too chaotic for me right now, I have to put something slow on' (Latoya, aged 19, USA) 
The respondents were highly aware of the music that would best serve their various needs as they sought to retain control over self and to care for themselves in daily contexts. They described how they knew that certain music would have particular 'effects' on them (for example, conjure up certain memories, or 'soothe' them) and they described how they associated certain music with particular social or personal tasks (the music of Enya, for example, was, for one respondent, music associated with bath time, and never with other times). In all of these examples, the music's 'effects' - what it came to afford were linked to the ways in which musical materials (e.g., the languorous melodies of Enya's slow numbers), biographical and situated couplings (e.g., the respondent first encountered Enya's music in a floatation tank), and generic/stereotypes associations associated with types of people, scenes, situations, moods). In all cases it was an admixture of music, connotations and consumption/production practices - the musical 'event' (DeNora 2003) that produced music's effects on actors. It was never 'music itself', nor merely interpretations/responses overlaid on that music (on the importance of avoiding these dual positions, see Hennion forthcoming).

It is important to develop this point: music's affordances are found in and through active practices of listening or otherwise appropriating music. This is a point well underscorred by many other researchers (Gomart and Hennion 1999; Hennion forthcoming; Greasley and Lamont (2006); Greasley in progress; Sloboda and O'Neill 2001; Batt-Rawden 2006a; 2006b; in press). Gomart and Hennion (1999), for example, have described the minute practices by which musical 'amateurs' or 'music lovers' construct the listening environment, the minute rituals through which the music's sacred or magical powers 'over' them are activated and in ways that are often then forgotten. As in DeNora (1999; 2000; 2001) they show how people, whether singly or in groups, draw together music and other materials in ways that provide mutual frames and that augment the ways in which those musics and materials seem 'fit' for the purpose. These practices of arrangement or, in Bruno Latour's term, assemblage (Latour 2005) are what empower music/materials in ways that come to have power over actors. Those actors are, in other words, colluding in their own subjection to musical/material 'control' (see DeNora 2000, Chapter 2 on this point). So, for example, when one respondent uses music so as to 'soothe' her, and to lower her stress levels before going out for the day, she not only chooses music that brings back comforting childhood memories of hearing her father play piano at bedtime (and he himself had chosen 'appropriately' soothing music for that hour some forty years earlier!), but she sets herself up in her living room, sitting in a rocking chair, 'nestled' as she puts it, between the stereo speakers. She does not, in other words, try to listen to this music for this purpose while engaging in some other busy or potentially stress-producing task, but is rather, active in crafting a specific type of musical event (DeNora 2003). 
To varying extents, the forms of emotional modification discussed above also involve corporeal modification. The informants in DeNora's music in everyday life study described how they sought to tap music's properties so as to affect bodily capacities - energy levels and motivation for exercise, for example:

Let's say I'm doing the warm-up. You want quite catchy music because some of [the class] are just not in the mood and if you've just got the drumming noise then you think, 'Oh, what the hell's going on? But I do it to motivate people...Let's say I've had a load of people who aren't really up for it and I've chosen a tape that's like OK, you find them just lolling around...[whereas] when they're doing sit ups...you need a lot of teaching points [instructions] and you...need [music] for a beat not to motivate them... (Sarah, aerobics teacher, UK).

Here, Sarah describes how careful music programming can enhance her aerobics students' motivation, and thus their bodily performance. In the fieldwork on aerobics, it became clear that music's role as a motivator and condition of bodily performance worked in ways that spoke directly to the body - for example, as contagious rhythm and as a structure capable of profiling bodily movement and as virtual reality, for example, providing the illusion of climbing, of covering ground or of gaining strength (DeNora 2000: 96-103). Music's role in the everyday world of physical labour further illustrates music's role as a prosthetic technology of the body, heightening and sustaining physical capacity, for example, when hoisting sails (shanties) or when weaving wool (DeNora 2000: 104-6).

Finally, music may help individuals to make knowledge, including self knowledge, and within this focus, to transcend difficult, stressful or extreme times and circumstances. It may also, adjacent to this task, facilitate narratives of self. For example, Lucy, one of the respondents in the music in everyday life study, can be seen here to elaborate her self-identity in relation to a musical structure, describing how she 'identifies' herself with the 'middle voices' in music:

I think that maybe that characterizes me in life, that I don't like being in the limelight, I like to..[pauses]...[be] part of a group. And, you know, pressing forward and doing my bit but not [pause]... seeing what needs doing and doing it but not being spotlighted and being 'out front' sort of thing (DeNora 2000:69).

In their work on music's role in social movement activity, Eyerman and Jamieson (1998) have described how music functions as an exemplars, by which they mean, in a sense akin to Thomas Kuhn's (1970), 'paradigm-constituting entities that serve to realign ...thinking' (Eyerman and Jamieson 
1998: 128). When musical materials provide the source of the exemplar, Eyerman and Jamieson, add, they not only have consequences for thinking, but are also consequential for living and feeling. In this brief example from one respondent, Lucy, we see music providing a metaphor that comes to structure or help to identify something extra-musical, namely, her personality - she is not someone to 'press forward' but rather, as she says in a later passage, someone who seeks to fill in the middle of things. In this way music provides a mirror, indeed, a kind of 'magic mirror' in which one may engage in problem solving and identity construction. The process was not dissimilar to that described by Bonde (2005) in a study of the Bonny Method of Guided Imagery and Music (BMGIM) and the development of imagery and narratives over time. In both the informal everyday life setting, and in GIM settings facilitated by music therapists, music can be seen to afford narrative construction through its connection (by participants themselves) to images, metaphors, scripts and narratives, and other cultural repertoires that promote rehabilitation, transcendence and general 'coping'.

In all of these examples above, focused on emotion regulation, body modification and narrative and cognitive development, we see music providing a self-stabilizing resource, one that is appropriated by respondents and used to achieve tasks that are linked to self-care and self-stability. While the link to health-status is only implicit in these examples, we can nonetheless see how music provides a typically tacit or unobserved resource for self-maintenance. This maintenance includes many aspects of self associated with mental health and mental strength, that is, with the ability to cope with adversity, stress-management, self-monitoring, and self-awareness. It is possible to see individuals here acting as lay-therapists to themselves and, sometimes (as when they deploy music to create ambience and scene) others. This skill is part of the lay methods by which actors take care of themselves, by which they foster continuous performances of self-stability and social competence. These skills are mostly sub-conscious, subsumed by other goals and tasks and deployed in response to the fluctuating, the local and the fleeting; they are not typically part of the skills that actors are aware of but rather they are operational skills (Batt-Rawden and DeNora 2005: 292). How, then, is it possible to see these skills being deployed in ways that are more overtly and explicitly linked to health? To explore this question, a recent study of music as a technology of health promotion for the chronically ill is now considered (Batt-Rawden 2006a; Batt-Rawden 2007; Batt-Rawden, DeNora and Ruud 2006; Batt-Rawden and DeNora 2005; Batt-Rawden 2006; Batt-Rawden and Tellnes 2005; Batt-Rawden and Aasgaard 2006). This study has developed the music 'as a technology of self' perspective via Even Ruud's focus on music as a 'health technology' by exploring musical activity explicitly in relation to self-therapy with an eye to policy recommendations for palliative care and, even more intriguingly, music's role - alongside more physical matters such as diet and exercise - as a means for health promotion 


\section{Music as a technology of health promotion in everyday life}

Outside the realm of music therapy, and with some very notable exceptions (Gouk 2000; Ruud 1997; Stige 2003; DeNora 2000; Sloboda and O'Neill 2001; Pavlicevic and Ansdell 2004) music's role as an everyday health technology outside of the hospital and medical/therapeutic arena has been a little studied topic. Batt-Rawden's recent work has helped to remedy this gap. Her study, an action research investigation, focused on how individuals could reflect and learn how to use music as a health technology so as to diminish or divert attention from symptoms, promote healthy behaviours and generally reconnect with self-narratives and self-identities linked to health and health promotion. The project drew together a sample of 22 Norwegian participants ${ }^{1}$ who were interviewed eight times over the course of a year. During this time, each participant was asked to contribute to the production of a series of CD compilations in which they shared, through the researcher as mediator, their musical loves, associations and memories. The point of the project was less to find out about 'how' they experienced music than to use this question as a springboard into a project of informal learning (BattRawden and DeNora 2005), to help participants discover and rediscover how to use music as a 'technology of the self' (DeNora 1999) and thus also as a 'cultural immunogen' (Ruud, 2002).

A wide range of 'uses' emerged from Batt-Rawden's interview data. For example, the participants described how they used, and learned how to use, music to cope with a range of tasks, problems and symptoms - for example, as a substitute for sleeping tablets, as a motivational device to 'move' out of low moods or depression, as a model or exemplar of where they hoped to be, as a reminder of how they 'could' be or were when 'at my best', as a way of 'dealing with' various problems and sorrows and as a medium through which they could connect with others, and virtually to each other via the CDs and through the researcher. In relation to connection to others, it is also possible to see here how the study of individual musical practice, as a health promoting technology, connects with a wider focus on music in the community and community music therapy, for example as collective identities and musical strategies can be seen to emerge within particular musical-social spaces (Trythall 2006; Stige 2003; Pavlicevic and Ansdell 2004; Bergh forthcoming)

1 Participants in the study were between 34 and 65 years of age, nine men and 13 women, of different socio-economic status. These were people suffering or recovering from some form of chronic illness (muscular disease, neurological disease, cancer, anxiety or depression, chronic fatigue), all of whom had previous experience of active music making (though some had to curtail musical activity due to illness) - ten played or sang, the remaining twelve were involved in folk clubs, choirs, concert attendance and home-listening 
Research participants also described how they used and/or learned to use music to modify the body, in particular to create relaxation, whether as part of preparation for sleep or as a way of 'forgetting' ones ills or as a way of redirecting attention away from distressing noises or thoughts. For example, Batt-Rawden describes how her research participants found, through music, new ways of solving practical problems that otherwise augmented their illness-status and did so in ways that allowed them the apparent reality of health. Central to this process was returning a sense of 'wholeness'. And at times the linking of music to other environmental affordances produced a (virtual? Or real?) sense of wellness, for example, here one participant describes how the combination of music and driving creates a feeling of freedom ('flying') and affords a space in which one is both in control and able to be expressive:

...when I fly away at high speed...it is lovely to listen to music. I feel I move in time and space and along with the music within me. I am singing in my car when I listen to my music...; (Batt-Rawden 2006a:105).

From stage to stage, as the CDs were distributed and discussed, the participants were encouraged to think about and describe the role music played in their lives and life histories, and how, increasingly, they used it to promote their own health. The various stages in this process highlight how participants' came to produce for themselves but with resources and models offered by the researcher modes of conscious awareness of music's 'powers' and skills of musical use over the course of the year-long project phase. In the process, they learned also how to adjust themselves, their environments and habits in relation to this new form of consciousness and the new skills of 'health musicking'. ${ }^{2}$

It is important to note that it was not music, per se, that achieved the outcome of connecting, of social recovery and Batt-Rawden's focus on the ritual features of music and self-healing illuminate this point clearly. For music to 'work' occasions and situations that empower it (and its makers/ recipients) need to be constituted; as with the work by DeNora, Gomart and Hennion, and Sloboda and O'Neill described earlier, music's affordances are created through the appropriation-work of users (the study participants) though it was greatly enabled by the facilitative work of the researcher and other participants who shared narratives, tips and pointers - all part of the informal learning of how to 'use' or appropriate music. ${ }^{3}$ Participants

2 Begrebet kan oversættes med 'sundheds-musicering'. Vedr. oversættelsen af begrebet 'musicking' til 'musicering', se s. 30.

3 Again, this work was accomplished by participants themselves, albeit facilitated by, in this case, the researcher, who presented her own 'health-musicking' as a model to her research participants. 
engaged in a process of informal learning about how to 'tell' about music's meaning and uses in their lives, thus creating for themselves (and for fellow participants) pointers and tips on how to use music so as to promote health and well-being, connection to others (specific and generalized) and selfempowerment, i.e., the ability to determine self-conditions, and also how to activate music such that it might 'work' in health-promoting or otherwise beneficial ways. And they referred to their musicking experiences in terms of 'high points', something to be valued, treasured. Batt-Rawden's work focused as well on the bridges participants made between music reception (listening) and music production (performing), and so illuminated the process of empowerment associated with active music listening. Learning how to use music as a platform for engaging in self-narrative and self-knowledge in turn motivated some participants to extend that learning and music activity to the realm of production, making their own musical resources. For example:

What I have gained through this project is to reinforce my belief that the strongest effect I gain from music is through playing and singing with other people, this synergy effect is like an encounter of love, it is so mysterious, just like somebody connects you to heaven, it is so strong this playing together, you know... (Male, 53, recovered from depression)

and:

The situation of being isolated from the work situation is not very pleasant. Through this project I have been able to contribute a lot and that means a lot to me. It has been very inspiring and also a huge contrast to being 'unable to work'. It has been very important to me that I have been able to focus on my resources and the kind of resources I have through music...huge contrast to my feelings of weariness and tiredness. This project has actually made me make contact with a folkmusic group in my community and now I am feeling so good. I have regained control and well-being in my life. It is great... (Female, 52, recovered from depression and severe back-pain two months before final round of fieldwork).

Here, we see how participation in the very creation of those materials that are then recursively used as affordance structures for health may be a vital feature in the form of empowerment that is linked to health promotion - ontological security and self-identity maintenance (Aasgaard 2002; 2004; Rolvsjord 2004; 2006). To be able to create, that is, to generate materials that 'fit' one's situation, and to hear/perceive oneself actually producing the very media that stabilize that self (i.e., to be able to creatively alter one's 
sonic/aesthetic environment) is a powerful resource - and a means by which one can demonstrate health-status (here as the ability to negotiate the - aesthetic - environment), one's ability, as a maker of one's world and thus, an author of the world as it affects oneself. In that transcendent moment one is actively performing self-health and it is in these mundane instances, often fleeting, that it is possible to see music's value in everyday, real-time healthcare.

\section{Conclusion}

If 'health' is health-status, that is, a meaningful entity that is affected recursively by self-meaning and interpretation and by previous attributions of health-status, and if it is performed in connection with resources, then it is of vital importance to 'un-pack' health performance and to investigate its constituent practices and the props through which health-performances are afforded. If music provides an important form of resource that affords or supports health, then the study of health-promotion needs to consider how music features in everyday care of self and health-performance in mundane settings. In DeNora's study, music afforded various personal enhancement features as well as a medium with which to set the scene for social encounters. In Batt-Rawden's study, music not only afforded care of self - as featured in DeNora's work $(2000 ; 2003)$ but also afforded social participation. Her research participants took delight in knowing they were (initially) virtually linked to each other through the researcher, through whom - and through their CD selections - they could communicate with each other (they agreed to meet in person at the project's end and some have remained in touch). Thus we see music providing social capital (Procter 2006; Putnam 2000), that is a medium of bonding which is itself a health resource. A focus on lay skill in music use, and on the craft of music therapists and affiliated health-music workers, as they assist individuals and groups to use music for self and community care is one way to create much needed 'bridgework' between the forms of musical activity that transpire in the treatment room, those that occur in community centres and those forms of everyday self-care that take place in a range of domestic and private settings where music can be seen to afford health-performances and health-statuses. By considering the often hidden lay-therapeutic functions music serves in everyday life, it is possible to return to music's use in hospital and therapeutic settings with new eyes, focusing on the role of the client/patient and what they bring to the music (therapeutic) event - their 'lay' craft. From there, it is also possible to see the craft of the music therapist or health-musician with new eyes as they seek to activate latent health-musicking skills in those with whom they work (Procter 2004; Trythall 2006). Everyday music practice is, in 
other words, a very rich seam for the study of human creativity and skill as applied to health performance and healing conduct.

\section{REFERENCES}

AASGAARD, T. (2004): A Pied Piper among White Coats and Infusion Pumps: Community Music Therapy in a Paediatric Hospital Setting. In Ansdell, G. \& Pavlicevic, M. (eds.) (2004), Community Music Therapy. London and Philadelphia: Jessica Kingsley Publishers.

AASGAARD, T. (2002): Song Creations by Children with Cancer - Process and Meaning. Thesis submitted for the degree of Doctor of Philosophy, Institute of Music and Music Therapy, Aalborg University.

BATT-RAWDEN, K.B \& DENORA, T. (2005): Music and Informal Learning in Everyday Life. Music Education Research, vol. 7, no. 3, pp. 289-304. London: Routledge.

BATT-RAWDEN, K.B. \& TELLNES, G. (2005a): Nature-Culture-Health Activities as a Method of Rehabilitation; An Evaluation of Participants' Health, Quality of Life and Function. International Journal of Rehabilitation Research, vol. 28, no. 2.

BATT-RAWDEN, K.B \& TELLNES, G. (2005b): Music and Health Promotion. A case study. In: Tellnes, Gunnar (Ed.). Urbanization and Health. New challenges to Health Promotion and Prevention. Oslo: Academic Press, UniPub.

BATT-RAWDEN, K.B. \& DENORA, T. \& RUUD, E.: (2005): Music Listening and Empowerment in Health Promotion; A study of the Role and Significance of Music in Everyday Life of the Long-term ill. Nordic Journal of Music Therapy; 14 (2): pp. 120-136.

BATT-RAWDEN \& AASGAARD, T. (2006): Music a Key to Kingdom. Electronic Journal of Sociology . http://www.sociology.org/content/2006/tier1/batt-rawden.html: ISSN - 11983655 - pp. 1-21.

BATT-RAWDEN, K.B. (2006a): Music and Health Promotion: The role and Significance of music and musicking in everyday life for the long term ill. $\mathrm{PhD}$ Thesis, submitted. University of Exeter.

BATT-RAWDEN, K.B. (2006b): Music - a strategy to promote health in rehabilitation? An Evaluation of participation in a 'Music and Health Promotion project'. International Journal of Rehabilitation Research, vol. 29 (2), pp. 171-173.

BATT-RAWDEN, K.B. (in press): Music as a transfer of faith - towards recovery and healing. Journal of Research in Nursing.

BERGH, A. (Forthcoming):. Music and Conflict Resolution. Music Scientif .

BONDE, L.O. (2005): »Finding a New Place... « Metaphor and Narrative in One Cancer Survivor's BMGIM Therapy. Nordic Journal of Music Therapy, 14 (2), pp. 137-154.

BROWN, S. \& T. THEORELL. (2006): The Social Uses of Background Music for Personal Enhancement. Pp 126-62 in S. Brown \& U. Volgsten (Eds.), Music and Manipulation: On the Social Uses and Social Control of Music. New York and Oxford: Berghahn Books.

CHAMBLISS, D. (1989): The mundanity of excellence: an ethnographic report on Stratification and Olympic Swimmers. Sociological Theory, vol. 7 (1), pp. 70-86.

CHAMBLISS, D. (1992): Reply to DeNora's Comment. Sociological Theory, vol. 10 (1) pp. 103-5.

DENORA, T. (1991): Comment on Chambliss' Mundanity of Excellence. Sociological Theory, vol. 10 (1), pp. 99-102.

DENORA, T. (1999): Music as a Technology of the Self. Poetics 27, pp. 31-56.

DENORA, T. (2000): Music in Everyday Life. Cambridge: Cambridge University Press. 
DENORA, T. (2001): Aesthetic agency and musical practice: new directions in the sociology of music and emotion. Pp. 161-80 in P. N. Juslin and J. A. Sloboda (eds) Music and Emotion: Theory and Research. Oxford: Oxford University Press.

EYERMAN, R. \& A. JAMIESON. (1998): Music and Social Movements. Cambridge: Cambridge University Press.

FREUND, P. (2001): Bodies, Disability and Spaces: the social model and disabling spatial organisations. Disability \& Society, vol. 16, no. 5, pp. 689-706.

GARFINKEL, H. (1968): Studies in Ethnomethodology. New York: Basic Books.

GIBSON, J.J. (1958): The Senses Considered as Perceptual systems. Boston: Houghton Mifflin.

GOFFMAN, E. (1961): Asylums. New York: Anchor Books.

GOMART, E. \& HENNION, A. (1999): »A sociology of attachment: music amateurs, drug users, « in J. Law and J. Hassard (eds.), Actor Network Theory and After. Oxford and Malden, MA: Blackwells, 220-247.

GOUK, P (Ed.). (2000): Musical Healing in Cultural Contexts. Aldershot: Ashgate.

GROCE, N. (2006): Everyone Here Spoke Sign Language: Cambridge, MA: Harvard University Press.

GREASLEY, A.E. \& LAMONT, A.M. (2006): Music preference in adulthood: why do we like the music we do? In Proceedings of the 9th International Conference on Music Perception and Cognition, (CD rom) (ed. M. Baroni, A. R. Addessi, R. Caterine \& M. Costa). Bologna, Italy: University of Bologna.

HENNION, A. (Forthcoming): Those Things that Hold Us Together: Taste and Sociology. Cultural Sociology, vol. 1 (1): 97-114.

HILBERT, R. (1986): Anomie and the Moral Regulation of Reality: The Durkheimian Tradition in Modern Relief. Sociological Theory 1986, vol. 4, no. 1, pp. 1-19.

HOCHSCHILD, A. (1983): The Managed Heart: commercialization of human feeling. Berkeley, Los Angeles and London: University of California Press.

MEHAN, H., A.HERTWECK \& J.L. MEIHLS. (1986): Handicapping the Handicapped: Decision Making in Students' Educational Careers. Stanford: Stanford University Press.

PAVLICEVIC, M. \& G. ANSDELL (eds.) (2004): Community Music Therapy. London and Philadelphia: Jessica Kingsley Publishers.

PROCTER, S. (2004): Playing Politics: Community Music Therapy and the Therapeutic Redistribution of Musical Capital for Mental Health. In: Pavlicevic, Mercedes \& Ansdell, Gary (Eds.). Community Music Therapy. London: Jessica Kingsley Publishers.

PROCTER, S. (2006): 'What are we playing at? Social capital and music therapy'. In Edwards, R.; Franklin, J. \& Holland, J. (eds) Assessing Social Capital: Concept, Policy and Practice. Cambridge: Cambridge Scholars Press.

PUTNAM, R (2000): Bowling Alone. New York: Simon and Schuster.

RADLEY, A. (1984): The embodiment of social relations in coronary heart disease. Social Science and Medicine 19, pp. 1227-34.

ROLVSJORD, R, (2004): Therapy as Empowerment. Clinical and Political Implications of Empowerment Philosophy in Mental Health Practices of Music Therapy. Nordic Journal of Music Therapy, vol. 13, no. 2, pp. 99-112.

ROLVSJORD, R. (2006): Whose Power of music? A Discussion on Music and PowerRelations in Music Therapy. British Journal of Music Therapy.

RUUD, E. (1997):. Music and Quality of Life. Nordic Journal of Music Therapy. vol. 6 (2), pp. 86-91.

RUUD, E. (2002): Music as a Cultural Immunogen - Three Narratives on the Use of Music as a Technology of Health. In: Hanken et al. (Eds.). Research in and for Higher Music Education. Festschrift for Harald Jørgensen. Oslo: NMH-Publications: 2. 
RUUD, E. (2004): Foreword: Reclaiming Music. In Pavlicevic, Mercédès and Ansdell, Gary (Eds.) (2004). Community Music Therapy. London and Philadelphia: Jessica Kingsley Publishers.

RUUD, E. (2005): Music: A salutogenic way to health promotion? . In Tellnes, G. (Eds.) Urbanization and Health. New challenges to Health Promotion and Prevention. Oslo: Academic Press, UniPub.

SLOBODA, J. \& S. O’NEILL (2001): Emotions in Everyday Listening to Music. In P. Juslin \& J. Sloboda, Music and Emotion: Theory and Research. Oxford: Oxford University Press.

SMALL, C. (1998): Musicking: The Meanings of Performing and Listening. Hanover: Wesleyan University Press.

STIGE, B. (2003): Elaborations towards a Notion of Community Music Therapy. Faculty of Arts, University of Oslo.

TRYTHALL, S. (2006): Live Music in Hospitals: A new 'alternative' therapy. The Journal of the Royal Society for the Promotion of Health; 126 (4): 113.

ZUBIETA, J.-K., J. BUELLER, L.R. JACKSON, D.J. SCOTT, Y. XU, R.A. KOEPPE, T.E. NICHOLS \& C.S. STOHLER (2005): Placebo Effects Mediated by Endogenous Opioid Activity on $\mu$-Opioid Receptors. Journal of Neuroscience 25: 7754-7762. 